\title{
IMPACTO DA INTERNET PARA OS MOVIMENTOS SOCIAIS E PARA A ABORDAGEM DA MÍDIA TRADICIONAL
}

\author{
Lucas Arantes Zanetti $^{1}$, Caroline Kraus Luvizotto ${ }^{2}$ \\ Universidade Estadual Paulista - UNESP, ${ }^{1}$ FAAC - Faculdade de Arquitetura, Artes e Comunicação. ${ }^{2}$ Programa de Pós- \\ Graduação em Comunicação, Presidente Prudente - SP. E-mail: lucaszanetti95@yahoo.com
}

\begin{abstract}
RESUMO
Este artigo busca analisar os impactos que a internet trouxe para os movimentos sociais, tanto na sua organização, quanto na sua abordagem midiática, com o intuito de entender a forma de atuação das manifestações sociais no novo milênio. Com o advento da internet a grande mídia perde seu monopólio, tornando a comunicação mais democrática - apesar de ainda ser segregativa e baseada na renda. O estudo foi desenvolvido por meio da pesquisa exploratória, descritiva e analítica de cunho qualitativo e os exemplos e objetos de estudo discutidos são as manifestações que ocorreram nos últimos anos como o Occupy Wall Street (EUA) e as manifestações brasileiras ocorridas no mês de junho de 2013, mostrando sua abordagem pela mídia e o peso que a internet teve no desenrolar dos acontecimentos.
\end{abstract}

Palavras-chave: Movimentos sociais; Internet; Comunicação Midiática.

\section{IMPACT OF INTERNET SOCIAL MOVEMENTS AND THE APPROACH OF TRADITIONAL MEDIA}

\begin{abstract}
This article seeks to analyze what were the impacts that the internet has brought to social movements, both in their organization and in their media approach, in order to understand the modus operandi of social events in the new millennium. With the advent of internet the mainstream media loses its monopoly, becoming the most democratic communication - although still segregationist and based on income. The study was developed through exploratory, descriptive and analytical qualitative research and the examples discussed and objects of study are the demonstrations that occurred in recent years as the Occupy Wall Street (USA) and Brazilian manifestations occurred in the month of June 2013, showing their approach by the media and the weight that the internet has had on the course of events.
\end{abstract}

Keywords: Social Movements; Internet; Communication media. 
CONSIDERAÇÕES INICIAIS: OS MOVIMENTOS

\section{SOCIAIS NA CONTEMPORANEIDADE}

Grande parte das revoluções sociais emergiram de uma situação insustentável para os oprimidos que, insatisfeitos, buscaram na luta - as vezes armada - uma maneira de adquirir o poder, visando melhores condições de vida e direitos, quase sempre ligados à liberdade.

O conceito de movimentos sociais surge num contexto pós-industrial, no qual a burguesia é a classe que detém poder e os meios de produção e passa a ser o agente explorador. A busca pela mudança não parte das classes altas, intelectuais, detentoras de grandes propriedades e capital, parte das massas operárias exploradas - por vezes analfabeta.

Na segunda metade do século $X X$, os movimentos sociais passaram a ter vertentes diferentes das causas operárias e de classe. Começam a surgir movimentos de cunho identitário e de liberdade individual como os movimentos feminista, hippie, homossexual e das comunidades periféricas. Estes e muitos outros movimentos passam a ser considerados pela Sociologia, a partir da década de 1970, como movimentos sociais contemporâneos, indicando que não apenas a luta de classes caracteriza os movimentos sociais (GOSS; PRUDÊNCIO, 2004).
Gohn (2003), define os movimentos sociais como "ações sociais coletivas de caráter sociopolítico e cultural que viabilizam formas distintas de a população se organizar e manifestar suas demandas" (GOHN, 2003 p.13)

Portanto, compreende-se que os movimentos sociais mudam de acordo com a mudança da sociedade. No caso dos movimentos de cunho identitário, cada grupo luta por interesses de liberdade individual, de auto-afirmação e em questões pragmáticas, justificadas por uma sociedade cada vez mais individualista. A demanda não é mais uma luta contra o sistema, mas sim de assegurar interesses dentro deste sistema.

Para Pereira (2011, p. 2), "o papel dos movimentos sociais contemporâneos é o de promover a democratização das relações sociais dentro da sociedade civil, através da redefinição de papéis, normas, identidades (individuais e coletivas) e interpretação de discursos existentes na esfera pública". E é assim que os movimentos se encontram com o advento da internet.

Ainda, segundo Rothberg, Luvizotto e Vanzini (2014, p. 229)

A dinâmica social contemporânea encontrase tracionada por movimentos sociais que se situam na condição de fontes de inovação e matrizes geradoras de 
saberes de caráter políticosocial, justificando a realização de análises que privilegiem o foco sobre as redes de articulações e de comunicação estabelecidas pelos movimentos em sua prática cotidiana. $O$ estudo de tais redes torna-se, assim, essencial para aproximar-se da compreensão de fatores que contribuem para desencadear aprendizagens e o surgimento ou a intensificação de valores de cultura política no processo de interação.

Por essa razão, justifica-se o estudo aqui apresentado e neste sentido, este artigo busca analisar os impactos que a internet trouxe para os movimentos sociais, tanto na sua organização, quanto na sua abordagem midiática, com o intuito de entender a forma de atuação das manifestações sociais no novo milênio. $O$ estudo foi desenvolvido por meio da pesquisa exploratória, descritiva e analítica de cunho qualitativo e os exemplos e objetos de estudo discutidos são as manifestações que ocorreram nos últimos anos como o Occupy Wall Street, ocorrido nos EUA e as manifestações brasileiras ocorridas no mês de junho de 2013, mostrando sua abordagem pela mídia e o peso que a internet teve no desenrolar dos acontecimentos.

\section{A ABORDAGEM MIDIÁTICA DOS MOVIMENTOS SOCIAIS}

A mídia sempre teve um grande poder na construção da opinião pública, pois é capaz de atribuir visibilidade aos fatos e descrevê-los a seu critério, sendo ela a maior - e muitas vezes única - fonte de informação das massas. Dessa maneira, desde sua popularização teve um papel importante na formação simbólica e política dos indivíduos, sendo representativa na mobilização ou desmobilização dos movimentos sociais.

A mídia também influencia na visão que a população terá dos movimentos sociais, buscando sempre sua supremacia e monopólio. Exemplo disso, é o caso do manifesto Occupy Wall Street ocorrido em 2011 nos EUA. Os manifestantes lutavam contra as desigualdades sociais e influências do poder privado em questões estatais. Logo, as manifestações também eram contra a própria mídia, acusada de ser subserviente aos poderosos interesses de corporações e governos. A imprensa americana se defendeu, reafirmando que o modelo de sociedade ocidental e democrático, com as instituições nacionais, é o mais sadio dentre todos modelos vigentes (SÔLHA, 2013). Após o episódio, a mídia americana fez forte trabalho de oposição aos movimentos sociais, acusando as manifestações de inconsistentes e sem sentido, tentando deslegitimar o movimento, como observa-se 
nesse trecho do artigo do jornal The Washington Post:

In New York, marchers chanted, "This is what democracy looks like," but actually, this isn't what democracy looks like. This is what freedom of speech looks like. Democracy looks a lot more boring. Democracy requires institutions, elections, political parties, rules, laws, a judiciary and many unglamorous, timeconsuming activities, none of which are nearly as much fun as camping out in front of St. Paul's Cathedral or chanting slogans on the Rue Saint-Martin in Paris (APPLEBAUM, 2011).

Neste caso, fica claro que na verdade o papel da mídia passa a ser de assegurar seus interesses em detrimento do compromisso com a verdade, não correspondendo à opinião pública, manipulando os fatos através de sua omissão e distorção. A jornalista coloca sua opinião de maneira debochada como se o Ocuppy Wall Street fosse um movimento sem sentido, ignorando a luta contra a desigualdade econômica, a ganância, a influência de grandes empresas no Estado e, coincidentemente, contra o monopólio midiático.

Algo semelhante ocorreu no Brasil nas manifestações de 2013, quando a mídia principalmente Globo e Veja - mudou sua posição em relação aos movimentos sociais. O jornalista e comentarista político Jabor (2013a), fez um comentário no Jornal da Globo do dia 12/06/13 criticando a ação dos manifestantes, no qual comparava-a com a ação da facção criminosa PCC, julgando a manifestação sem sentido: "a causa (das manifestações) é a ausência da causa", afirmou. Além disso, é possível observar uma certa manipulação no rumo dos manifestos em sua fala, quando ele afirma: "porque não lutam contra a proposta de emenda constitucional 37 , que impede o ministério público de investigar? Talvez eles (os manifestantes) nem saibam o que é a PEC37, a lei a impunidade eterna." Em menos de uma semana, Jabor (2013b), já tinha se desculpado e admitido seu erro, afirmando algo totalmente contrário à sua posição inicial, dessa vez defendendo a manifestação: "Mas a partir de quinta-feira, com a violência maior da Polícia, ficou claro que o Movimento Passe Livre expressava uma inquietação que tardara muito no País." Além disso, fez outras reflexões comparando o movimento com os caras pintadas, dessa vez defendendo a falta de rumo dos manifestantes, antes criticada. Disso, pode-se tirar duas conclusões: na primeira fala do jornalista, ele tenta, em seu discurso, criar um sentido para as manifestações, com a ideia da PEC37, manipulando os telespectadores à lutarem por algo que julga 
necessário. Em sua retratação, observa-se uma mudança estratégica da emissora ao lidar com as manifestações, visto que o público não aderiu à ideia e a Globo passou, inclusive, a ser alvo das manifestações. $\mathrm{Na}$ semana seguinte a manifestação, uma das novas reivindicações populares era a queda da PEC37, mostrando o poder de influência que a mídia possui.

\section{INTERNET: UMA NOVA FONTE DE INFORMAÇÃO}

Segundo seus criadores, a internet é uma mídia que agrega todas as outras e permite a interação entre seus usuários, independente de sua localização geográfica (INTERNET SOCIETY, 2003). Assim, as formas de comunicação e consumo de informação começam a se modificar, deixando de ser unilaterais - marcados pelos meios de comunicação de massa - e passam a ser algo participativo e democrático, a partir do uso das tecnologias web 2.0. Devido à interatividade, com a criação das redes sociais e blogs, a internet proporciona a todos seus usuários capacidade de produzir informação, ao invés de somente consumi-la. Ou seja, o internauta pode expressar livremente a posição, opinião e relato que achar conveniente, sem precisar passar por edição de uma linha editorial e de jornalistas como acontece no espaço reservado ao leitor das revistas e jornais, ou uma entrevista na TV e no rádio.

De acordo com Rothberg, Luvizotto e Vanzini (2014, p. 231):

Os recursos da web 2.0 facilitaram a criação e a circulação de conteúdos aos usuários da internet, que podem atuar como leitores, autores, produtores e editores de conteúdo informacional multimídia. $\mathrm{O}$ usuário não é mais pensado como agente passivo, mas como desenvolvedor de conteúdo. A segunda geração de ferramentas online potencializa as formas de publicação, compartilhamento e organização de informações, além de expandir os espaços para a colaboração entre os participantes.

Por meio da internet mídias alternativas surgiram e emergiram na sociedade e como ferramenta de apoio e organização de diversos movimentos e grupos sociais. A própria população passou a incorporar o papel dos jornalistas, usando seus aparatos tecnológicos. Dessa forma, no caso das manifestações ocorridas no Brasil em meados de 2013, vídeos onde era mostrado o abuso do poder policial foram feitos e alcançaram grande visualização. As manifestações contaram com cobertura integral por parte de mídias como a mídia NINJA (Narrativas Independentes de 
Jornalismo e Ação). Neste caso, não havia como distorcer os fatos, pois havia material suficiente para contestar a versão dos grandes veículos de comunicação. Nos comentários nas páginas da internet, a população contestava e acusava os veículos de manipulação. Algo inédito, possível somente em uma plataforma como a internet.

A democratização dos meios de comunicação proporcionada pela internet que não é total, pois não é de acesso a todos - retoma uma esfera pública de debate independente vinculado aos cafés e praças do séc. XVIII, perdido com o advento dos meios de comunicação de massa (EISENBERG, 2003). Com a internet, o debate se amplifica e se intensifica, gerando frutos para a vida em sociedade, mudando a experiência de interação dos indivíduos.

A internet estremece o monopólio midiático dos meios de comunicação de massa - que controlam a opinião pública e identidades individuais e coletivas oferecendo um campo de discussão e a publicização da informação, sendo um mecanismo contra a alienação. Mas vale lembrar que a internet é algo muito recente e de acesso restrito, e que portanto ainda há muito o que analisar até que se possa compreender totalmente seus impactos. Além disso, a internet não pressupõe necessariamente que seus usuários vão ter acesso às informações contidas nos ambientes informacionais digitais, dependendo do indivíduo buscar isso. Ou seja, ela é uma ferramenta livre que pode ou não ser usada - e se usada não necessariamente para escapar das rédeas dos meios de comunicação de massa.

\section{CONSIDERAÇÕES FINAIS}

O campo da internet é algo novo e ainda não é possível medir totalmente quais são seus impactos para a organização e atuação dos movimentos sociais. Mas, com o seu surgimento, é possível perceber que eles não se organizam e nem atuam da mesma forma, tendo como exemplo as manifestações citadas no texto.

O fluxo de informação é cada vez maior. Somos bombardeados a todo momento com informações e descobertas e dessa vez não há monopólio, sendo possível um cidadão comum fazer um trabalho jornalístico. Vídeos do abuso da polícia contra a população nas manifestações brasileiras se popularizaram e impediram qualquer tentativa de manipulação por parte da grande mídia. Tudo isso, atrelado às ferramentas da internet, fazem com que o círculo de ideias se renovem, colaborando também para manifestações políticas e sociais.

Através deste estudo, fica claro tanto a necessidade de mudança da abordagem 
dos meios de comunicação de massa, uma vez que a formação da opinião pública fica cada vez menos por conta destes veículos, quanto à nova estrutura organizacional dos movimentos sociais. Dessa forma, a grande mídia precisa se renovar, para evitar o que já está acontecendo: as pessoas estão abandonando os veículos tradicionais. Isso se expressa nas quedas drásticas de índices de audiência, venda de exemplares, e fechamento de veículos jornalísticos.

A internet, além de trazer todas as mídias juntas, tem um potencial que nenhum meio de comunicação teve até o momento: ser democrático. Isso configura uma nova abordagem por parte da grande mídia se ela pensa em sobreviver, pois não é mais possível manipular totalmente as pessoas devido à nova fonte de informação, caracterizada pela colaboração, pela inteligência coletiva e pela interatividade.

Sem dúvida, ainda há muitas mudanças pela frente, pois não há acesso universal à internet, devido às barreiras estruturais, tecnológicas, econômicas e sociais, e ainda estamos longe de democratizá-la a esse ponto. Todavia, a internet pode servir como elemento reconfigurador, no qual a partir dela própria possa colaborar para a mudança desse quadro, como consequência do fortalecimento dos movimentos sociais e de seu consequente ganho de força.

\section{REFERÊNCIAS}

APPLEBAUM, Anne. What the Occupy protests tell us about the limits of democracy. Washingnton Post, 2011. Disponível em: $<$ http://articles.washingtonpost.com/201110-17/opinions/35278895_1_spanishprotests-online-video-democracy> Acesso em: 12 dez. 2013.

EISENBERG, José. Internet, democracia e República. Dados, Rio de Janeiro, v. 46, n. 3, 2003 . Disponível em <http://www.scielo.br/scielo.php?script=sci_ arttext\&pid=S0011-

$52582003000300003 \& \operatorname{lng}=e n \& \mathrm{nrm}=\mathrm{iso}>$.

Acesso em: 11 ago. 2014.

GOHN, Maria da Glória. Movimentos sociais no início do século $\mathbf{X X I}$ : antigos e novos atores sociais. Petrópolis: Vozes, 2003.

GOSS, Karine Pereira; PRUDENCIO, Kelly. O conceito de movimentos sociais revisado. Revista eletrônica dos Pós-Graduandos em Sociologia Política da UFSC, v. 2, n. 1, p. 7591, jan./jul. 2004.

INTERNET SOCIETY. Briefy History of Internet. Washingnton, 2003. Disponível em: <http://www.internetsociety.org/internet/w hat-internet/history- internet/brief-historyinternet> Acesso em: 12 dez. 2013.

JABOR, Arnaldo. Comentário sobre as manifestações de junho no Jornal da Globo. Rio de Janeiro, 12/06/13. 2013a. Disponível em <http://www.youtube.com/watch?v=oCduMlugRI>. Acesso em: 12 dez. 2013.

JABOR, Arnaldo. Retratação sobre comentários do Jornal da Globo, na rádio CBN. São Paulo, 17/06/13. 2013b. Disponível em:

<http://www.youtube.com/watch?v=_7fc0Th H2uU>. Acesso em: 12 dez. 2013.

PEREIRA, Marcus Abílio. Internet e mobilização política: os movimentos sociais 
na era digital. In: ENCONTRO DA COMPOLÍTICA. ASSOCIAÇÃO BRASILEIRA. DE PESQUISADORES EM COMUNICAÇÃO E POLITICA, 4., 2011, Rio de Janeiro. Anais... Rio de Janeiro: Universidade do Estado do Rio de Janeiro, 2011.

ROTHBERG, Danilo; LUVIZOTTO, Caroline Kraus; VANZINI, Kátia Viviane da Silva. As revoltas e seu impacto sobre a comunicação pública: o potencial do Observatório Participativo da Juventude. Liinc em Revista, v. 10, n. 1, p. 227-240, 2014.

SÔLHA, Hélio Lemos. 'Media' e as Manifestações de Junho: controle e disputa. Observatório da Imprensa, São Paulo, n. 769, 22 out. 2013.

Recebido para publicação em 18/08/2014 Aceito em 26/08/2014 